\title{
Pseudohypoparathyroidism with paradoxical increase in hypocalcaemic seizures due to long-term anticonvulsant therapy
}

\author{
Alan Glynne \\ B.Sc., M.B., Ch.B.(Edin.), M.R.C.P.(Lond.)
}

IAIN P. HUNTER*

B.D.S.

\author{
JoHN A. THOMSON \\ M.D., F.R.C.P.(Glasg.), M.R.C.P.(Lond.) \\ University Department of Medicine, Glasgow Royal Infirmary, and \\ University Department of Oral Medicine and Oral Pathology, \\ Glasgow Dental Hospital, Glasgow
}

\begin{abstract}
Summary
A case of pseudohypoparathyroidism is described. Unusual features included the apparent absence of a familial history and the long delay in clinical diagnosis. Dental evidence is presented which dates the metabolic abnormality back to at least the age of 2 , yet symptoms did not appear until the age of 12 and the correct diagnosis was not made until she was 32 . The role of long-term anticonvulsant therapy in the paradoxical exacerbation of the patient's hypocalcaemic seizures is discussed.
\end{abstract}

\section{Introduction}

Pseudohypoparathyroidism is a rare disorder first described in 1942 (Albright et al., 1942). The biochemical features of true hypoparathyroidism, hypocalcaemia and hyperphosphataemia, are found together with various somatic abnormalities. The disorder is usually considered to be inherited as a sex-linked dominant trait (Mann, Alterman \& Hill, 1962) and the diagnosis is made in the typical patient at the age of 5-10 years (Rasmussen, 1968). Hypocalcaemic convulsions may be the major practical problem for the patient. The following patient is particularly interesting in that the diagnosis was not made until she was 32 years old and that there appears to be no familial history. There is also the intriguing probability that the epileptiform seizures, which were the main clinical problem, were increased in frequency because of a further decrease in her serum calcium level, consequent upon the long-term ingestion of a combination of phenobarbitone with phenytoin and, more recently, with primidone (Kruse, 1968; Richens \& Rowe, 1970).

\footnotetext{
* Requests for reprints: Dr Alan Glynne, University Department of Medicine, The Royal Infirmary, 86 Castle Street, Glasgow, C.4.
}

\section{Case report}

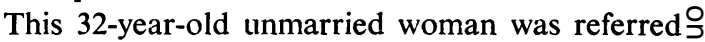
to Glasgow Royal Infirmary in May 1970 because of $\rightarrow$ a marked increase in frequency of her grand malO seizures. These had begun when she was aged 120 years but she had only experienced two or three $\mathbb{D}$ seizures each year. For very many years she hagl $\overrightarrow{\overrightarrow{0}}$ been treated continually with phenobarbitone $30 \operatorname{lng} \theta$ three times daily and phenytoin sodium 100 m three times daily. In January 1970 she began to have an ever-increasing number of convulsions despite an increase in dosage of her anticonvulsant medication and a substitution of primidone $250 \mathrm{mg}$ three times $\stackrel{0}{0}$ daily for her phenytoin. When first seen at this $\stackrel{\square}{\square}$ hospital she was having seven or eight seizures daily. $\overrightarrow{\vec{O}}$

The previous history revealed that she had always $\frac{0}{3}$ been mentally retarded and short in stature. Her menarche occurred normally at the age of 12 years. In 1962 it was noted that she had bilateral lenticular cataracts which were situated in the posterior cortex of the lens. These were removed in 1966. For about the last 5 years she had complained of frequent cramps in the hands and there was little doubt in $\delta$ retrospect that she was describing carpal spasm.

On physical examination she was very small, being 울 only $4^{\prime} 9^{\prime \prime}$ with a crown-to-pubis height of $30^{\prime \prime}$ and a pubis to ground height of $27^{\prime \prime}$. Her span was disproportionately small being only $55^{\prime \prime}$ and she had a squat habitus, her weight being $55 \mathrm{~kg}$. The hands and $\sigma$ feet were very stubby, all the metacarpals and meta- $N$ tarsals being short. There was excessive pigmentation $\mathrm{N}$ around pressure areas. Chvostek's and Trousseau's signs were markedly positive. There was no evidence of oral or systemic candidiasis.

Initial serum calcium levels varied between 5.0 and $6.0 \mathrm{mg} / 100 \mathrm{ml}$. The alkaline phosphatase was normal at $9 \mathrm{KAU} / 100 \mathrm{ml}$. Serum albumin was $4 \cdot 2$ $\mathrm{g} / 100 \mathrm{ml}$ and serum globulin $3.0 \mathrm{~g} / 100 \mathrm{ml}$. The 
urinary calcium excretion on a normal ward diet containing $800 \mathrm{mg}$ of calcium was low at $15.0 \mathrm{mg} / 24 \mathrm{hr}$. The blood urea was $18 \mathrm{mg} / 100 \mathrm{ml}$ and creatinine clearance $104 \mathrm{ml} / \mathrm{min}$. The urinary hydroxyproline excretion was $33.4 \mathrm{mg} / 24 \mathrm{hr}$ (normal range 10-47 $\mathrm{mg} / 24 \mathrm{hr}$ for a female) (Benoit, Thiel \& Watten, 1963). EEG: long episodes of high voltage delta activity which had a rhythmic quality. ECG: prolonged QT interval with widespread inversion and flattening of $T$ waves. These changes were consistent with hypocalcaemia. She had a normal female karyotype.

Radiology of the skull showed widespread intracranial calcification, most marked in the basal ganglia (Fig. 1). Dental radiography demonstrated the presence of nine unerupted teeth, some of which were displaced from their normal positions. Hypoplastic changes could be seen in the crowns, especially of the third molars. The roots appeared shortened and an element of root resorption could be seen. The surrounding alveolar bone was normal in radiographic appearance (Fig. 2). Radiology of the hands revealed shortening of the metacarpals with some periarticular diminution in bone density (Fig. 3).

An Ellsworth-Howard test was performed (Ellsworth \& Howard, 1934). The mean basal urinary excretion of phosphorus over a 3-hr period was $392.2 \mu \mathrm{g} / \mathrm{min}$. After the intravenous infusion of 200 USP units of bovine parathormone, there was a mean excretion of urinary phosphorus of $723.0 \mu \mathrm{g} /$ min over a 4 -hr period, i.e. 1.8 times the mean basal level. There was no increase in the serum calcium. A healthy control subject had a mean basal urinary excretion of phosphorus of $208.2 \mu \mathrm{g} / \mathrm{min}$. After an identical infusion of the same parathormone there was a mean excretion of urinary phosphorus of 474.0 $\mu \mathrm{g} / \mathrm{m} ı n$, i.e. $2 \cdot 3$ times the mean basal level. There was no increase in the creatinine clearance of either our patient or the control subject.

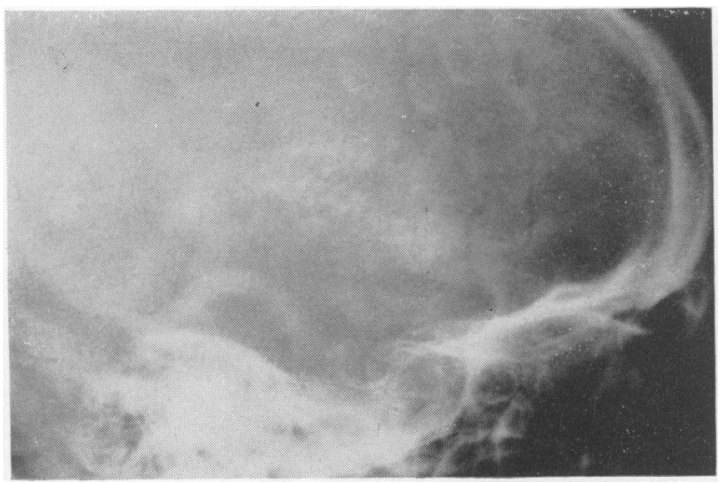

FIG. 1. Enlarged detail of calcification in basal ganglia.
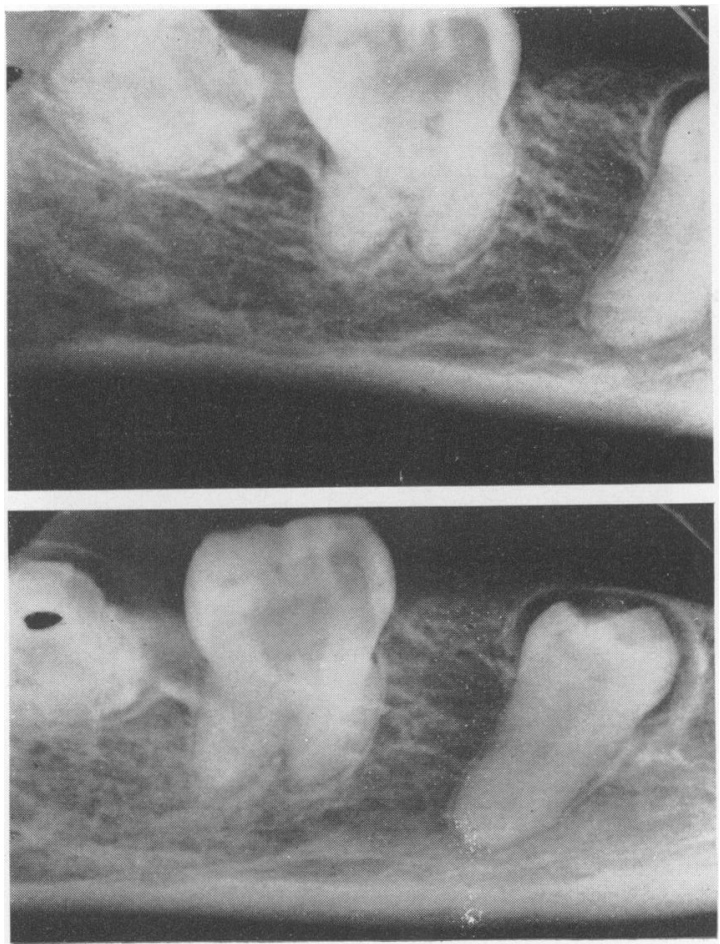

Fig. 2. Dental radiograph showing hypoplasia and root shortening.

The plasma concentration of immuno-reactive parathormone was $0.57 \mathrm{ng} / \mathrm{ml}$ at a time when the serum calcium was low at $7.6 \mathrm{mg} / 100 \mathrm{ml}$. The normal range in normocalcaemic patients is 0.10 to 0.35 $\mathrm{ng} / \mathrm{ml}$ (Buckle, 1971, personal communication).

Family history. Her mother was only $4^{\prime} 11^{\prime \prime}$ in height but had no somatic or skeletal abnormalities. Her serum calcium, inorganic phosphate and alkaline phosphatase were normal. There was one male sibling who lived abroad and so could not be examined. However, he was said to be $6^{\prime} 0^{\prime \prime}$ in height and to be completely healthy. The father had died of a myocardial infarction aged 52 years but was said to have been tall and healthy.

Response to treatment. Treatment was commenced with vitamin $\mathbf{D}_{2}$ (strong calciferol B.P.) in a dose of 50,000 units daily. After increasing the vitamin $D_{2}$ to 100,000 units daily her serum calcium rose to $9 \cdot 1$ $\mathrm{mg} / 100 \mathrm{ml}$ and her serum inorganic phosphate fell to $4.6 \mathrm{mg} / 100 \mathrm{ml}$. The frequency of her seizures decreased dramatically and indeed she has had none at all during the last 12 months. During this time her phenobarbitone and primidone had been withdrawn. She has had no anticonvulsant therapy for the last 4 months.

Dental histology. When she had been rendered 


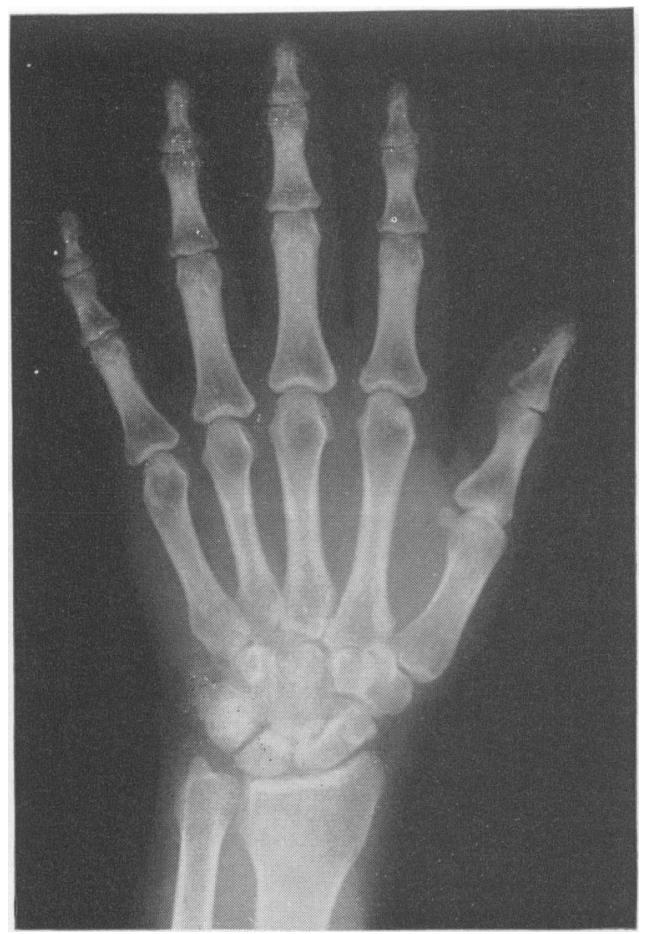

FIg. 3. Radiograph of hand showing shortening of the metacarpals and peri-articular loss of bone density.

normocalcaemic her unerupted teeth were removed surgically because she was suffering a great deal of discomfort. Furthermore, it is a well recognized feature that cystic change in the reduced enamel epithelium of unerupted teeth can lead to pathological fracture of the mandible (Stones, 1966). Histological examination of ground sections of these teeth showed generalized pitting hypoplasia of the enamel. It was in the dentine, however, that the changes were most pronounced, particularly the extensive pattern of interglobular dentine where the normal tubular arrangement of growth had been replaced by the less ordered type of dentinogenesis. As sections nearer the pulp were examined the tubular growth pattern became more indistinct (Fig. 4).

\section{Comments}

The combination of the various somatic, biochemical and radiological abnormalities suggested the diagnosis of pseudohypoparathyroidism, despite the apparent absence of familial history. The finding of a raised plasma immunoreactive parathormone level in the presence of hypocalcaemia indicated active parathyroid glandular activity as is found in pseudohypoparathyroidism (Chase, Leland-Melson \& Aurbach, 1969). Moreover, our patient's kidneys were relatively refractory to infused parathormone. It was originally suggested that the pathophysiology of the disorder could be attributed to refractoriness of the receptor tissues to the action of parathormone (Albright et al., 1942). More recently it has been shown that there is a defective urinary excretion of cyclic adenosine $3^{\prime}, 5^{\prime}$-monophosphate, suggesting that the metabolic defect of the disorder should be accounted for by a lack of, or defective form of parathyroid-hormone-sensitive adenylcyclase in kidney and bone (Chase et al., 1969).

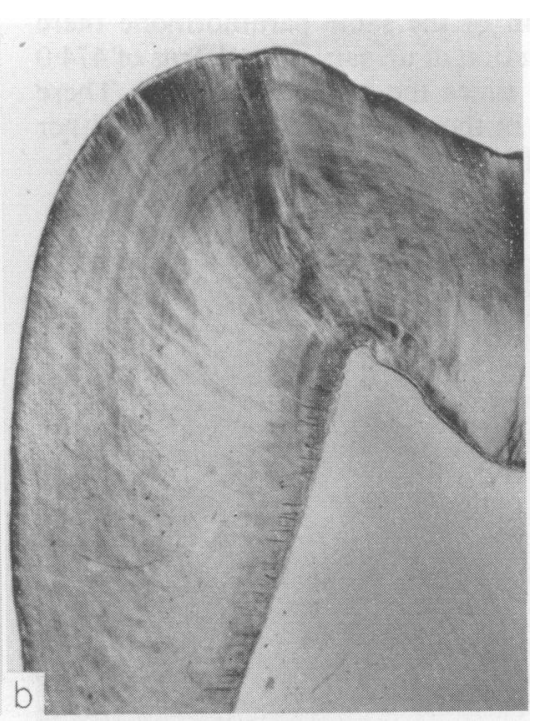

F!G. 4. (a) Ground section of abnormal tooth showing enamel hypoplasia and dentine malformation. (b) Ground section of a normal tooth for comparison with (a). 
The radiographic appearances of pseudohypoparathyroidism as it affects the teeth have been described (Sunde \& Hals, 1961; Croft, Witkop \& Glas, 1965; Bronsky, 1958) and the following abnormalities noted: delayed eruption; multiple retention of unerupted teeth; root resorption; severe enamel hypoplasia and enamel aplasia. Clinically the presentation of this case was not until 12 years but from the enamel hypoplasia on the erupted teeth it is clear that some upset in calcium and phosphorus metabolism had been present from at least the age of 2. The lack of any further dental information prevents the history being extended back any further. Information is inconclusive concerning the level to which serum calcium must fall and the length of time it must remain lowered before dental mineralization abnormalities may occur. It is possible that decreases which are insufficient to cause neuromuscular excitability may still cause dental defects (Greenberg et al., 1969). The dentine changes are more pronounced than those in enamel (Sunde \& Hals, 1961). It is thought that this may be a manifestation of the gradual loss of the property of specialization of the odontoblast as a result of the biochemical consequences of the condition. On the other hand it has been claimed that the hypoplastic changes are not an essential feature of pseudohypoparathyroidism (Witkop, 1968).

The arrested root development may be due to a defect in Hertwig's root sheath, that part of the tooth germ responsible for root formation (Sunde \& Hals, 1961). The displacement of the unerupted teeth from their normal position has been recorded (Cranin \& Katz, 1967) and is seen in our case. This is not, of course, a specific feature of pseudohypoparathyroidism and may be seen in other circumstances where there has been gross irregularity in the mechanism of eruption. The most prominent feature of the dental involvement is the facility which it gives to the clinician in early diagnosis. We are unaware of any abnormalities in this case before the age of 2 years, but perhaps if observation had been made of hypoplastic pitting on the deciduous teeth and delay in eruption of the permanent series, dental radiography could have aided an earlier diagnosis.

Certainly it is noteworthy that the presence of chronic hypocalcaemia was not revealed until the patient was 32-years old. Although the condition is rare, the occurrence of cataracts in a young epileptic should lead the clinician to suspect the possiblity of a hypocalcaemic state.

This patient was on anticonvulsant therapy for many years and experienced only two or three seizures each year. However, early in 1970 there was an increase in the number of seizures and accordingly her anticonvulsant therapy was increased by her family doctor. Paradoxically, rather than bringing about improvement, the frequency of her seizures was increased dramatically and to such an extent that seven or eight convulsions were occurring daily. Once correction of her hypocalcaemia was achieved with vitamin $D$ therapy she had no further convulsions and her anticonvulsant therapy was withdrawn completely.

There can be little doubt that her epileptiform seizures were due to hypocalcaemia. The deterioration after many years may have been due to a further and critical decrease in her serum calcium level. Recently it has been demonstrated that long-term anticonvulsant therapy, particularly when more than one drug is used, can precipitate hypocalcaemia (Kruse, 1968; Richens \& Rowe, 1970), and this may well have been the mechanism in our patient. The means by which this phenomenon is brought about may be the induction of hepatic microsomal enzymes leading to the accelerated breakdown of vitamin D to inactive products (Dent et al., 1970; Hunter et al., 1971). In these circumstances the daily requirement for vitamin $D$ would be increased and it has indeed been shown that large doses of the vitamin will correct the hypocalcaemia (Richens \& Rowe, 1970).

In view of the above background knowledge and our own experience with this particular case we would recommend that before commencing anticonvulsant therapy in an epileptic patient, hypocalcaemia should be excluded. This should also be done in patients whose seizures are becoming more frequent despite an increase in anticonvulsant drugs. More generally, one may speculate whether the instability and difficulty in control of some idiopathic epileptics may be partly related to the precipitation of hypocalcaemia by the long-term use of many commonly used anticonvulsant drugs. Estimation of serum calcium levels may prove to be helpful in the management of some unstable and difficult epileptics, particularly those who take a diet poor in vitamin $\mathrm{D}$ and who are not exposed to very much sunlight.

\section{Acknowledgments}

We would like to express our thanks to Professor E. M. McGirr for permission to publish details of this case and to Dr R. M. Buckle of Southampton General Hospital for the estimation of the plasma immuno-reactive parathormone level.

\section{References}

Albright, F., Burnett, C.H., Smith, P.H. \& Parson, W. (1942) Pseudohypoparathyroidism-and example of 'Seabright-Bantam syndrome'. Endocrinology, 30, 922

Benoit, F.L., Thiel, G.B. \& WATten, R.H. (1963) Hydroxyproline excretion in er,docrine disease. Metabolism, 12, 1072.

BRONSKY, D. (1958) Idiopathic hypoparathyroidism and pseudohypoparathyroidism, case report and review of the literature. Medicine (Baltimore), 37, 317.

Chase, L.R., Leland Melson, G. \& Aurbach, G.D. (1969) Pseudohypoparathyroidism. Defective excretion of $3^{\prime}, 5^{\prime}$ - 
AMP in response to parathyroid hormone. Journal of Clinical Investigation, 48, 1832.

Cranin, A.A. \& Katz, H.E. (1967) Pseudohypoparathyroidism-Report of a case. Journal of the American Dental Association, 74, 741.

Croft, L.K., Witkop, C. J. JR, \& Glas, J. (1965) Pseudohypoparathyroidism. Oral Surgery, 20, 758.

Dent, C.E., Richens, A., Rowe, D.E.J. \& Stamp, T.C.B. (1970) Osteomalacia with long-term anticonvulsant therapy in epilepsy. British Medical Journal, 4, 69.

EllSWORTH, R.\& HowARD, J.E. (1934) Studies on the physiology of the parathyroid glands. VII. Some responses of normal human kidneys and blood to intravenous parathyroid extract. Bulletins of Johns Hopkins Hospital, 55, 296.

Greenberg, M.S., Brightman, V.J., LYNCH, M.A. \& ShIP, J.I. (1969) Idiopathic hypoparathyroidism, chronic conditions and dental hypoplasia. Oral Surgery, 28, 42.

Hunter, J., Maxwell, J.D., Stewart, D.A., Parsons, V. \& Williams, R. (1971) Altered calcium metabolism in epileptic children on anticonvulsants. British Medical Journal, 4, 202.
KRUSE, R. (1968) Osteopathien bei antiepileptischer langzeittherapie (Vorlanfige Mitteillung). Mschr Kinderheilk, 116, 378.

Mann, J.B., Alterman, S. \& Hill, A.G. (1962) Albright's hereditary osteodystrophy comprising pseudohypoparathyroidism and pseudopseudohypoparathyroidism. Annals of Internal Medicine, 56, 315.

RASMUSSEN, H. (1968) In: Textbook of Endocrinology (Ed. by Robert H. Williams), p. 920. W. B. Saunders Company, Philadelphia, London, Toronto.

RicheNS, A.S. \& RowE, D.J.E. (1970) Disturbance of calcium metabolism by anticonvulsant drugs. British Medical Journal, 4, 73.

StONES, H.H. (1966) In: Oral and Dental Disease (Ed. by E. D. Farmer and F. E. Lanton) p. 869. E. and S. Livingstone.

Sunde, D.E. \& Hals, E. (1961) Dental changes in a patient with hypoparathyroidism. British Dental Journal, 111, 112.

WITKoP, C.J. (1968) Gardner's syndrome and other osteognathodermal disorders with defects in parathyroid function. Journal of Oral Surgery, 26, 639.

\title{
Calcification of the basal ganglia apparently presenting as a schizophreniform psychosis
}

\author{
Peter Hall \\ M.B., Ch.B., Ph.D., M.R.C.Psych., D.P.M.
}

\section{Powick Hospital, Worcester}

\section{Summary}

A patient with gross basal ganglia calcification is described, whose condition was associated with severe psychotic symptoms and in whom the clinical picture was not typical of hypoparathyroidism, pseudohypoparathyroidism or pseudo-pseudohypoparathyroidism.

Calcification of the basal ganglia may occur in a variety of infections, toxic and metabolic disorders, particularly hypoparathyroidism, pseudohypoparathyroidism, toxoplasmosis and some anoxic conditions (Moskowitz, Winickoff \& Heinz, 1971).

Though there is doubt as to the precise diagnosis in the present case, familial calcification appears to be the most probable.

\section{Case history}

Mrs X, a 41-year-old widow, wrote to the Medical Officer of Health in 1955 in the belief that her three children had venereal disease and were also suffering from cancer. She believed that their condition was infectious, that things had gone too far for anything to be done for them and that the local people grinned and whispered behind their hands when they passed and that she and the children would suffer an early, lonely and agonizing death because of her wickedness in having had two illegitimate children. She had heard voices at night commenting on her 'pink eyes' (which she regarded as a sign of venereal disease) and also had visual hallucinations of 'worms everywhere'. A diagnosis of schizophrenia was made and she was treated as an in-patient by electroconvulsive therapy with some imrpovement. She was re-admitted in September 1963 in a cachectic, dehydrated and pitiable state; whimpering, grimacing and protruding her tongue. Her auditory hallucinations this time were of voices saying 'act normal' and she was treated with thioridazine and further ECT and was discharged, apparently much improved after some weeks.

She was again admitted in April 1965 when she was disorientated in time and place, grossly dysarthric, apparently demented and with marked parietal lobe dysfunction. She improved with antiParkinsonian drugs but not sufficiently to cope with her home and was placed in a Local Authority Home but was once again admitted in December 1970 after she had become very restless and paranoid. On this occasion she showed extreme dysarthria and oral dyskinesia, an upper motor neurone right-sided facial palsy and moderately severe right-sided hemiparesis. She also again believed that she was suffering from venereal disease. Psychological testing (WAIS) showed her to have a verbal IQ of 82 , a performance IQ of 69 and marked impairment of visuo-spatial 